\title{
Persisterende ductus arteriosus en pulmonalisstenose bij een labrador-retriever
}

\author{
Patent ductus arteriosus and pulmonic stenosis in a Labrador retriever
}

\author{
${ }^{1}$ S. Vester, ${ }^{1}$ S. Pil, ${ }^{1}$ V. Liekens, ${ }^{1}$ B. Van Goethem, ${ }^{2}$ A. Binetti, ${ }^{3}$ J. Saunders, ${ }^{1}$ P. Smets
}

\author{
${ }^{1}$ Vakgroep Kleine Huisdieren \\ ${ }^{2}$ Vakgroep Heelkunde en Anesthesie van de Huisdieren, \\ ${ }^{3}$ Vakgroep Medische Beeldvorming van de Huisdieren en Orthopedie van de Kleine Huisdieren \\ Faculteit Diergeneeskunde, Universiteit Gent, Salisburylaan 133, B-9820 Merelbeke
}

\section{AMENVATTING}

Een drie maanden oude, vrouwelijke, intacte labrador-retriever werd doorverwezen wegens een vermoedelijk congenitaal hartprobleem. Klinische symptomen waren niet aanwezig, maar op het lichamelijk onderzoek werd een luide, continue hartruis met fremitus opgemerkt (graad 5 op 6) ter hoogte van de linkerhartbasis. Door middel van echocardiografie werd de diagnose van persisterende ductus arteriosus (PDA) en pulmonalisstenose (PS) gesteld. Anderhalve maand na de initiële presentatie werd de PDA chirurgisch gesloten. De PS werd medicamenteus behandeld met de $B$-blokker atenolol en werd verder opgevolgd om de respons op deze therapie en de eventuele noodzaak van een ballonvalvuloplastie te evalueren. Deze casus toont aan dat een kwalitatief en volledig echocardiografisch onderzoek steeds noodzakelijk is bij een jong dier met een hartruis. Ook wanneer de oorzaak van de hartruis snel geïdentificeerd kan worden, in het voorliggende geval persisterende ductus arteriosus, moet er gecontroleerd worden op eventuele bijkomende afwijkingen, zoals hier pulmonalisstenose.

\section{ABSTRACT}

A three-month-old, female, entire, Labrador retriever was presented after being referred because of a suspected congenital heart disorder. The dog did not show any symptoms, but on clinical examination, there was a loud continuous heart murmur with a thrill present (grade 5 out of 6), located at the left heart base. Echocardiographic examination revealed the presence of a patent ductus arteriosus (PDA) and pulmonic stenosis (PS). One and a half month after initial presentation, the PDA was surgically closed. The PS was treated with the B-blocker atenolol and followed up to evaluate the response to therapy and the potential need for a balloon valvuloplasty. This case demonstrates the necessity of a qualitative and complete echocardiographic evaluation in young dogs with a heart murmur. Even if the cause of the heart murmur can easily be identified, in the present case patent ductus arteriosus, it is important to screen for additional abnormalities, as in this case pulmonic stenosis.

\section{INLEIDING}

Persisterende ductus arteriosus (PDA) en pulmonalisstenose (PS) behoren beide tot de top drie van meest voorkomende congenitale cardiovasculaire aandoeningen bij de hond (Schrope, 2015). Toch wordt het simultane voorkomen van beide aandoeningen weinig beschreven in de literatuur (Patterson et al., 1968; Johnson et al., 2004; Johnson en Martin, 2004; Oliveira et al., 2011).
Persisterende ductus arteriosus ontstaat wanneer de embryonale ductus arteriosus niet sluit binnen één week na de geboorte (Patterson et al., 1971). Hierdoor blijft er een vasculaire shunt aanwezig tussen de arteria pulmonalis en de aorta, wat grote gevolgen heeft voor de druk ter hoogte van de longbloedvaten en leidt tot volumeoverbelasting van het linkerhart (Buchanan, 2001) (Figuur 1). Pulmonalisstenose is een vernauwing net proximaal (supravalvulair) ter hoogte van (valvulair) of juist distaal (subvalvulair) van de pul- 

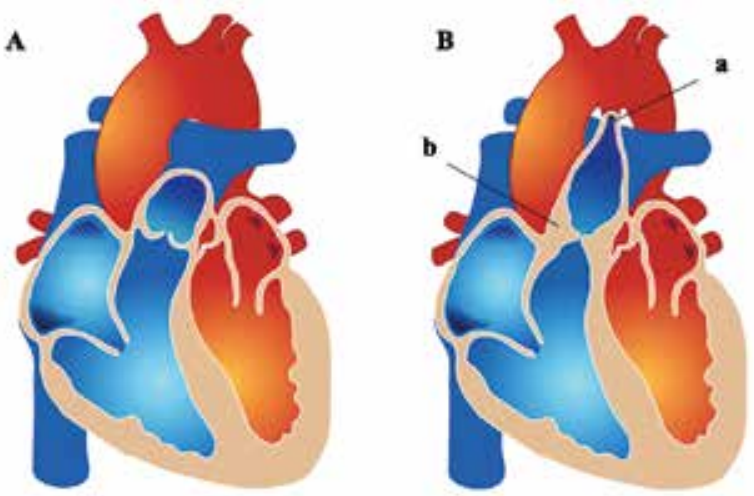

Figuur 1A. Normaal hart. B. Hart met (a) een persisterende ductus arteriosus en (b) valvulaire pulmonalisstenose.

monalisklep (Kittleson en Kienle, 1998) (Figuur 1). Deze stenose kan het gevolg zijn van dysplasie en partiële fusie van de pulmonalisklepbladen, waarbij deze variabel verdikt zijn, de annulus van de pulmonalisklep normaal breed is en er post-stenotische dilatatie aanwezig is van de truncus pulmonalis (type A). In sommige gevallen is er echter eerder sprake van variabel verdikte dysplastische klepbladen samen met hypoplasie van de pulmonalisklep annulus, zonder post-stenotische dilatatie (type B). Gemengde types (tussen A en B) worden bij de hond ook regelmatig gezien (Patterson et al., 1981; Bussadori et al., 2001). In tegenstelling tot PDA leidt PS tot concentrische hypertrofie van het rechterhart (Kittleson en Kienle, 1998).

In verschillende studies werd onderzoek gedaan naar de genetische achtergrond en de erfelijkheid van deze aandoeningen bij de hond. Uit proefkruisingen is gebleken dat het voor beide afwijkingen om een multifactoriële aandoening gaat, waarbij zowel het milieu als de genetische basis invloed heeft op het voorkomen ervan. Over de exacte genen die betrokken zouden zijn, is echter tot op heden nog weinig bekend (Patterson et al., 1971; Patterson et al., 1981). Daarnaast is er geslachtspredispositie, waarbij PDA voornamelijk bij vrouwelijke honden voorkomt (Lamy et al., 1957; Buchanan, 2001; Van Israël et al., 2002), en PS eerder bij mannelijke honden wordt gezien (Malik et al., 1988; Tidholm, 1997; Bussadori et al., 2001; Oliveira et al., 2011; Schrope, 2015).

De behandeling van PDA bestaat uit het sluiten van de vasculaire shunt, wat door middel van chirurgische ligatie of door interventionele katheterocclusie kan gebeuren (Kittleson en Kienle, 1998). Bij aanwezigheid van PS wordt, afhankelijk van de ernst van de stenose, gekozen voor een medicamenteuze therapie met een ß-blokker of interventionele ballonvalvuloplastie om zo de regio van de pulmonalisklep te verwijden (Bussadori et al., 2001; Johnson et al., 2004; Johnson en Martin, 2004). De prognose van de interventionele behandeling van PS varieert van goed tot gereserveerd en is minder gunstig wanneer gelijktijdig andere hartafwijkingen aanwezig zijn (Johnson en
Martin, 2004). De prognose van het sluiten van PDA is daarentegen uitstekend (Buchanan, 2001).

\section{CASUSBESCHRIJVING}

Een drie maanden oude, vrouwelijke, intacte, labrador-retriever van negen kilogram werd doorverwezen omwille van een hartruis, die op zes weken leeftijd werd vastgesteld. Een nestgenoot werd reeds gediagnosticeerd met tricuspidalisinsufficiëntie (vermoedelijk ten gevolge van tricuspidalisdysplasie). Deze vertoonde symptomen van rechterhartfalen en werd geëuthanaseerd. De hond in de huidige casus had echter geen gezondheidsklachten en vertoonde normaal puppygedrag. Benauwdheid en syncopes kwamen volgens de eigenaar nooit voor.

Op het lichamelijk onderzoek was de hond alert, de ademhalingsfrequentie was 48 ademhalingen per minuut, de hartfrequentie 80 slagen per minuut, de kleur van de slijmvliezen was roze en de capillaire vullingstijd was minder dan 2 seconden. De "body condition score" werd geschat op 5 op 9 (Freeman et al., 2011). De perifere pols was egaal, regelmatig, symmetrisch en krachtig geslagen. Er was geen polsdeficit aanwezig. Ook was er geen venenpols zichtbaar en de undulatieproef was negatief. De ictus cordis was links palpabel en op auscultatie was er een continue hartruis hoorbaar met een fremitus, graad 5 op 6. Het punctum maximum bevond zich links ter hoogte van de hartbasis.

Om de oorzaak van de hartruis op te sporen, werd een echocardiografie uitgevoerd. De subjectieve bevindingen waren volumeoverbelasting van het linkerventrikel en matige concentrische hypertrofie van het rechterventrikel; daarbij waren het linker- en rechter-atrium normaal van grootte. Als verklaring voor de volumeoverbelasting van het linkerventrikel kon een PDA met een ostium van 4,2 $\mathrm{mm}$ in beeld worden gebracht (Figuur 2). Vervolgens werd als oorzaak van de hypertrofie van het rechterventrikel PS

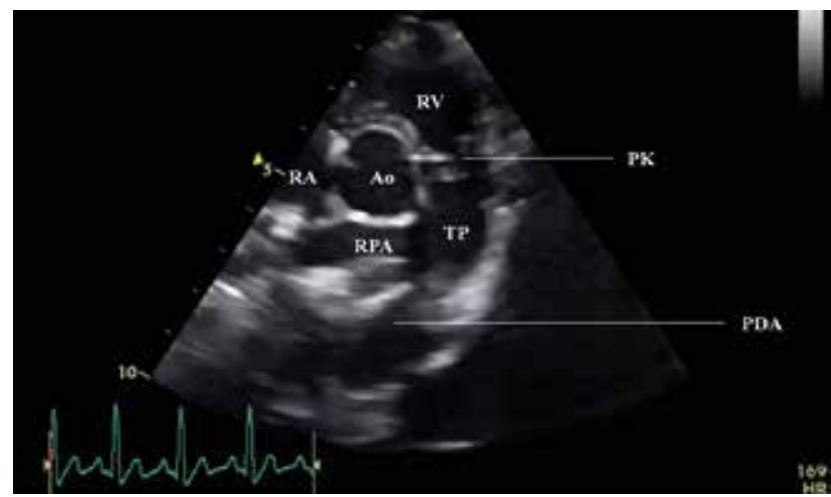

Figuur 2. Tweedimensionaal echocardiografisch beeld. Rechter parasternale dwarse doorsnede ter hoogte van de pulmonaalarterie waarop zowel PDA als een abnormaal verdikte pulmonalissklep (PK) zichtbaar zijn.

RV: rechterventrikel, $R A$ : rechteratrium, RPA: rechterpulmonaalarterie, TP: truncus pulmonalis en Ao: aorta. 
opgemerkt, waarbij de pulmonalisklep matig verdikt was met "systolic doming" (Bussadori et al., 2000) en abnormale opening (fusie) van de klepbladen (Figuur 2). Dopplerechografie toonde een fysiologische snelheid in de aorta en een turbulente flow in de arteria pulmonalis met een verhoogde snelheid $(4,57 \mathrm{~m} / \mathrm{s} \sim$ drukgradiënt van $84 \mathrm{mmHg}$ ), wat volgens Kittleson en Kienle (1998) dient te worden beschouwd als erge PS (>80 mmHg) (Figuur 3). Tweedimensionale en Mmode-metingen bevestigden de volumeoverbelasting en een mild verlaagde systolische functie van het linkerventrikel. De diagnose na het echocardiografisch onderzoek was dan ook de aanwezigheid van PDA in combinatie met erge valvulaire PS type A.

Op een leeftijd van vier maanden werd bij de hond een chirurgische ligatie van de PDA uitgevoerd. Op dat moment waren er evenmin gezondheidsklachten gerelateerd aan de hartafwijkingen die aanwezig waren. De hond kreeg bij opname reeds twee weken 2 $\mathrm{mg} / \mathrm{kg}$ furosemide (Libeo, Ceva Santé Animale S.A./ N.V., Brussel, België) tweemaal daags toegediend, ter preventie van het ontstaan van longoedeem gezien de ademhalingsfrequentie thuis in rust verhoogd was. Op het lichamelijk onderzoek waren de ademhalingsfrequentie en de hartfrequentie iets hoger dan bij het vorige bezoek, respectievelijk 60 en 140 per minuut. De lichaamstemperatuur bedroeg $39,3^{\circ} \mathrm{C}$. Verder werden er geen nieuwe abnormaliteiten opgemerkt.

Preoperatief werd het echocardiografisch onderzoek herhaald en tevens werd een elektrocardiogram (ECG) uitgevoerd, waarop meerdere ventriculaire premature complexen (VPC's) gezien werden. Op het echocardiografisch onderzoek werd dit maal ook turbulente flow gezien proximaal van de pulmonalisklep, wat deed vermoeden dat er naast valvulaire PS, ook een subvalvulaire component aanwezig was. Daarnaast werd er een iets hogere snelheid ter hoogte van de arteria pulmonalis gemeten $(4,79 \mathrm{~m} / \mathrm{s} \sim$ drukgradiënt van $92 \mathrm{mmHg}$ ). De overige bevindingen kwamen overeen met deze van het eerder uitgevoerde echocardiografisch onderzoek.

Ter voorbereiding van de anesthesie werd een perifere veneuze katheter (Jelco IntuitIV Safety Catheter $^{\mathrm{TM}}$, Jelco ${ }^{\circledR}$, Wheeling, Verenigde Staten) van 22 gauge geplaatst in de linker vena cephalica en als premedicatie werd $0,2 \mathrm{mg} / \mathrm{kg}$ methadon (Comfortan, Dechra Veterinary Products, Northwich, Verenigd Koninkrijk) intraveneus (IV) toegediend. Gedurende vijf minuten werd de hond gepreoxygeneerd met $2 \mathrm{~L} / \mathrm{min}$ $100 \%$ zuurstof via een gezichtsmasker en vervolgens werd de anesthesie geïnduceerd met $4 \mathrm{mg} / \mathrm{kg}$ propofol (Propovet Multidose, Equphar N.V./S.A., Oostkamp, België) IV. Onmiddellijk daarna werd geïntubeerd met een $7 \mathrm{~mm}$-interne diameter gecuffte endotracheale tube (Curity ${ }^{\mathrm{TM}}$ Tracheal Tube, Kendall, Verenigde Staten). De anesthesie werd verder onderhouden met isofluraan (Isoflo, Aesica Queensborough Limited, Kent, Engeland) verdampt in $100 \%$ zuurstof met behulp van een "circle rebreathing system"-anesthesie-

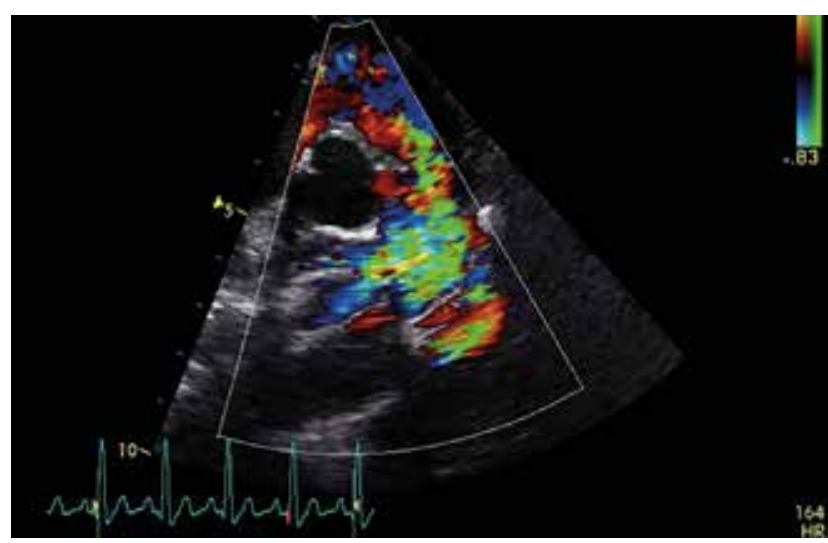

Figuur 3. Kleurendopplerechocardiografisch beeld. Rechter parasternale dwarse doorsnede ter hoogte van de pulmonale arterie waarop de turbulentie, veroorzaakt door zowel PDA als PS, zichtbaar is (groene kleur).

toestel (Cicero, Dräger Medical, Lubbeck, Duitsland). De monitoring van de patiënt bestond uit pulsoxymetrie, elektrocardiografie, capnografie, invasieve bloeddrukmeting en oesofagale temperatuursmeting. Om analgesie te bekomen, werd een CRI van fentanyl (Fentadon, Dechra Veterinary Products, Northwich, Verenigd Koninkrijk) opgestart aan een snelheid van $5 \mu \mathrm{g} / \mathrm{kg} / \mathrm{uur}$, na eerst een ladingsdosis te hebben toegediend van $2 \mu \mathrm{g} / \mathrm{kg}$. Eenmalig werden er $20 \mathrm{mg} / \mathrm{kg}$ cefalosporines (Cefazoline, Sandoz GmbH., Kundl, Oostenrijk) en $4 \mathrm{mg} / \mathrm{kg}$ carprofen (Rimadyl, Zoetis S.A., Louvain-la-Neuve, België) IV toegediend. Voor de start van de chirurgie werd de patiënt op gecontroleerde ventilatie geplaatst met een tidaal volume van $10 \mathrm{ml} / \mathrm{kg}$ en een piek inspiratoire druk tussen 11 en 16 $\mathrm{mmHg}$. De ademhalingsfrequentie tijdens de ingreep was 15 tot 17 ademhalingen per minuut en de eind tidale $\mathrm{CO}_{2}$ bevond zich tussen 49 en $54 \mathrm{mmHg}$. Tijdens de anesthesie werden er enkele geïsoleerde VPC's opgemerkt; hier werd geen bijkomende medicatie voor opgestart.

$\mathrm{Na}$ het scheren, reinigen en de desinfectie van het operatieveld werd aan de linkerzijde een intercostale block uitgevoerd ter hoogte van de derde tot en met de zevende intercostale ruimte met behulp van $4 \mathrm{mg} / \mathrm{kg}$ lidocaïne (Xylocaïne ${ }^{\circledR} 2 \%$, AstraZeneca, Cambridge, Verenigd Koninkrijk). De thorax werd geopend in de linker vierde intercostale ruimte. Na het plaatsen van een finochietto-ribspreider werd het voorste deel van de linker craniale longkwab atelectatisch gemaakt en naar achteren geklapt. Inspectie van de bloedvaten en het hart toonde dilatatie van zowel de aortaboog (voor de ductus) als de arteria pulmonalis. De ductus werd gelokaliseerd, zorgvuldig vrijgeprepareerd en dubbel afgebonden met $2 / 0$ polydioxanone (PSDII, Ethicon, Verenigde Staten) (Figuur 4). Op dit moment verplaatste het punt van maximale fremitus zich van de ductus naar de arteria pulmonalis. De long werd weer in zijn anatomische positie gebracht en de thorax werd gesloten door enkelvoudige circumcostale hech- 


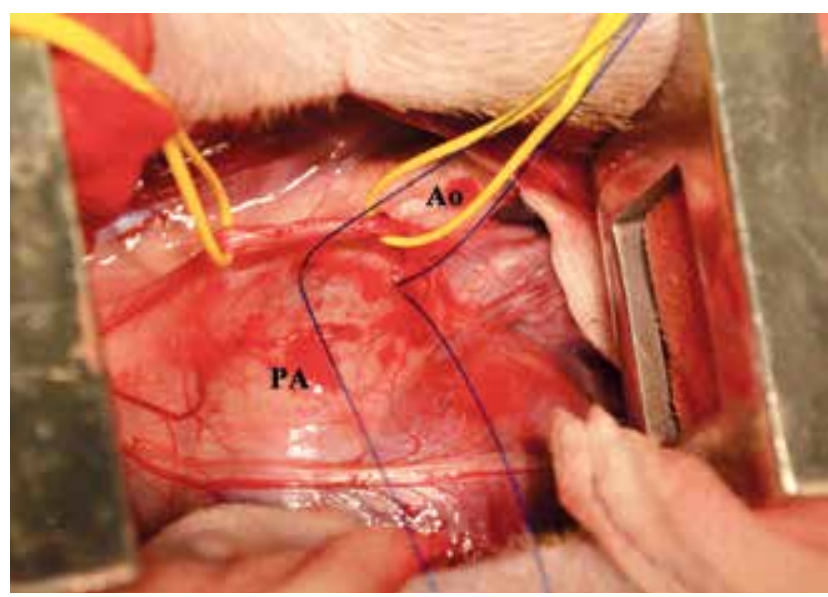

Figuur 4. Intraoperatieve afbeelding waarbij het hart vanaf de linkerzijde benaderd wordt. Gele lijnen: rond N. vagus, dubbele ligaturen: rond PDA. Ao: gedilateerde aortaboog, PA: arteria pulmonalis.

tingen (2/0 polydioxanone (PSDII, Ethicon, Verenigde Staten)) en een doorlopende hechting op de intercostaal spier (4/0 polyglecaprone (Monocryl, Ethicon, Verenigde staten)). De aanwezige lucht werd met een tijdelijke drain geëvacueerd. De overige spierlagen (M. serratus ventralis en M. latissimus dorsi) werden beide doorlopend gesloten met 3/0 polydioxanone (PSDII, Ethicon, Verenigde Staten) en de subcutis en huid elk doorlopend met 3/0 polyglecaprone (Monocryl, Ethicon, Verenigde Staten). De recovery van de patiënt verliep voorspoedig en zonder complicaties.

$\mathrm{Na}$ de operatie werd er opnieuw een cardiologisch onderzoek uitgevoerd, waarbij er op het ECG geen VPC's meer konden worden vastgesteld. Op de echocardiografische beelden was te zien dat de PDA gesloten was zonder resterende flow (Figuur 5). De overige subjectieve tweedimensionale bevindingen waren gelijk aan deze van het preoperatief echocardiografisch onderzoek. Hieruit werd geconcludeerd dat de PDA succesvol was gesloten, maar dat er nog steeds erge PS aanwezig was.

De hond werd één nacht ter observatie gehospitaliseerd met een onderhoudsinfuus (Vetivex Hartmann's Solution, Dechra Veterinary Products, Northwich, Verenigd Koninkrijk) en analgetische medicatie bestaande uit 0,2 mg/kg methadon (Comfortan, Dechra Veterinary Products, Northwich, Verenigd Koninkrijk) IV om de vier uur en $2 \mathrm{mg} / \mathrm{kg}$ carprofen (Rimadyl, Zoetis, België) per os (PO) tweemaal daags. Een dag later werd de hond ontslagen met de volgende pijnmedicatie: $5 \mathrm{mg} / \mathrm{kg}$ tramadolhydrochloride (Tramadol EG, Eurogenerics NV, België) PO driemaal daags gedurende drie dagen en $2 \mathrm{mg} / \mathrm{kg}$ cimecoxib (Cimalgex, Vétoquinol, Verenigd Koninkrijk) PO eenmaal daags gedurende zeven dagen. Vóór de PS werd een therapie opgestart met atenolol (Atenolol, Sandoz B.V., Duitsland) PO via een opbouwend schema over vijf weken (tussen de 1 en $2 \mathrm{mg} / \mathrm{kg} / \mathrm{dag}$, steeds aan te passen volgens de groei). De eigenaar werd geadviseerd

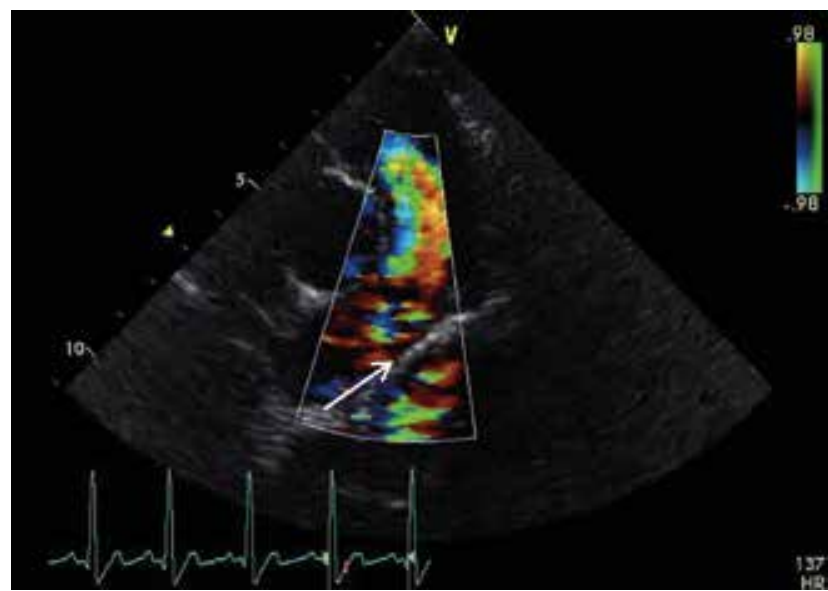

Figuur 5. Kleurendopplerechocardiografisch beeld. Rechter parasternale dwarse doorsnede ter hoogte van de arteria pumonalis waarop te zien is dat de PDA gesloten is (pijl), maar de turbulentie veroorzaakt door de PS nog steeds aanwezig en zichtbaar is (groene kleur).

contact op te nemen indien de hond lethargisch zou worden of andere symptomen zou vertonen, zoals inspanningsintolerantie, hoesten of syncopes.

Op de controleafspraak acht weken later waren er nog steeds geen klachten aanwezig gerelateerd aan een verminderde hartfunctie en was de hond actief en speels. Op klinisch onderzoek werden er, behalve een systolische hartruis van graad 4 op 6, geen afwijkingen gevonden. Er werd opnieuw echocardiografisch onderzoek uitgevoerd, waarbij geen duidelijke verschillen konden worden opgemerkt in vergelijking met de postoperatieve beelden. De drukgradiënt ter hoogte van de pulmonalisklep was zeer mild gedaald (van $92 \mathrm{mmHg}$ naar $88 \mathrm{mmHg}$ ), maar het ging hierbij om een klinisch niet relevant verschil. De huidige dosis van $1 \mathrm{mg} / \mathrm{kg} / \mathrm{dag}$ atenolol (Atenolol, Sandoz B.V., Duitsland) werd via een opbouwend schema over vier weken verhoogd naar $2 \mathrm{mg} / \mathrm{kg} / \mathrm{dag}$.

Zeven maanden na de operatie werd de PS nog verder opgevolgd. In eerste instantie werd atenolol opgestart om de drukgradiënt ter hoogte van de pulmonalisklep te verlagen. Indien dit later niet voldoende zou blijken, i.e. het optreden van klinische symptomen, progressief ergere remodelering van het rechterhart of het optreden van significante tricuspidalisinsufficiëntie, moet behandeling door middel van ballonvalvuloplastie overwogen worden.

\section{DISCUSSIE}

PDA en PS zijn beide veel voorkomende congenitale hartafwijkingen (Schrope, 2015). Een combinatie van beide aandoeningen komt echter zeer weinig voor.

Typisch voor PDA is een luide continue hartruis, zoals aanwezig bij de hond van de beschreven casus (Stephenson, 2012). Bij puppy's kan, tot een leeftijd van enkele maanden, een fysiologische hartruis 
aanwezig zijn, maar het gaat hierbij echter vrijwel steeds om een mild systolische hartruis (graad 1 of 2 , sporadisch graad 3) (Côté et al., 2015). Andere differentiaaldiagnosen voor een continue hartruis zijn een geruptureerde sinus van Valsalva, een arterioveneuze fistel in de thorax, een ventriculair septumdefect met aortaklepregurgitatie, aortastenose met aortaklepregurgitatie en PS met pulmonalisklepregurgitatie. De eerste twee afwijkingen zijn echter zeldzaam bij de hond en de laatste drie geven eerder twee losstaande ruizen tijdens zowel systole als diastole (Kittleson en Kienle, 1998). Waar zeker rekening mee gehouden dient te worden is dat de continue luide hartruis bij PDA (ook wel 'machinery murmur' genoemd) een hartruis van een bijkomend aanwezige afwijking kan maskeren. Echocardiografisch onderzoek is dus noodzakelijk om een juiste en volledige diagnose te kunnen stellen (Patterson, 1968; Kittleson en Kienle, 1998).

Uit een studie van Oliveira et al. (2011) blijkt dat meerdere congenitale hartafwijkingen vaak samen voorkomen, voornamelijk bij de aanwezigheid van PS. In combinatie met PS kwam aortastenose in de studie het meeste voor $(11,6 \%)$, maar ook een ventrikelseptumdefect $(5,2 \%)$ en tricuspidalisklepdysplasie $(0,8 \%)$ werden gezien. Pulmonalisstenose in combinatie met PDA was bij 2,8\% van de honden met een congenitale hartafwijking aanwezig. Daarnaast kunnen bij zowel PDA als PS bijkomende afwijkingen, zoals mitralisklepdysplasie en atriaal septumdefect, voorkomen (Johnson en Martin, 2004; Oliveira et al., 2011).

De prognose voor PDA en voor PS is erg verschillend. Beide aandoeningen kunnen, zoals bij de hond van de beschreven casus, symptoomloos aanwezig zijn (Tidholm, 1997; Buchanan, 2001). Dit wordt voornamelijk gezien wanneer het om een hond vóór zijn eerste levensjaar gaat en het, in het geval van PS, een milde tot matige graad betreft (Johnson et al., 2004). Symptomen die bij PS op een latere leeftijd of bij een ergere graad kunnen optreden, zijn onder andere inspanningsintolerantie, syncopes of plotselinge sterfte (Johnson et al., 2004). Pulmonalisstenose bij de hond kan echter ook asymptomatisch blijven (Tidholm, 1997). Daarentegen geeft PDA op termijn vrijwel steeds symptomen, zoals inspanningsintolerantie, groeiachterstand of dyspnee ten gevolge van pulmonair oedeem (Buchanan, 2001). Om deze reden wordt behandeling van PDA altijd aangeraden.

In het voorliggend geval werd er gekozen voor chirurgische ligatie van de PDA. De prognose van het chirurgisch sluiten van PDA is zeer goed. Zelfs behoorlijke veranderingen ter hoogte van het hart, bijvoorbeeld linkeratriumdilatatie, kunnen volledig reversibel zijn. Wanneer enkel PDA aanwezig is, verdwijnt in de meeste gevallen de hartruis vrijwel onmiddellijk na het sluiten van de vasculaire shunt en het hart neemt na ongeveer drie maanden weer zijn normale volume aan (Buchanan, 2001).
Uit een studie van Francis et al. (2011) blijkt dat honden met PS en een drukgradiënt hoger dan 60 $\mathrm{mmHg}$ een verhoogde kans hebben op hartfalen (met $86 \%$ sensitiviteit en $72 \%$ specificiteit) en daarom baat zouden kunnen hebben bij een interventionele behandeling. De resultaten van deze studie dienen echter genuanceerd te worden en in de meeste gevallen wordt er rekening gehouden met meerdere criteria om al dan niet een ballonvalvuloplastie uit te voeren. Naast de ernst van de PS uitgedrukt volgens de drukgradiënt, wordt er rekening gehouden met de leeftijd van de hond, de aanwezigheid van klinische symptomen, de aanwezigheid van andere congenitale hartaandoeningen of van significante tricuspidalisklepinsufficiëntie en uiteraard ook met de wensen van de eigenaar. In de beschreven casus werd besloten om de PS niet interventioneel te behandelen en verder op te volgen door middel van regelmatige echocardiografische controles. Zowel tijdens de eerste als tweede controleafspraak, respectievelijk twee en vijf maanden postoperatief, vertoonde de hond geen klinische symptomen en werden er geen significante echocardiografische veranderingen opgemerkt. De PS werd nog verder opgevolgd om de noodzaak van een eventuele ballonvalvuloplastie in te toekomst te evalueren.

In de literatuur bestaat er enige onduidelijkheid over het effect van ß-blokkers bij de aanwezigheid van PS. Het verandert niets aan de stenose zelf, maar omdat het door de negatieve inotrope en chronotrope werking de zuurstofbehoefte van het hart vermindert en de hartfunctie ondersteunt, kan het worden toegepast om een patiënt langer symptoomloos te houden (Kittleson en Kienle, 1998). Bij honden met PS werden nog geen overtuigende wetenschappelijke studies uitgevoerd waarin een overlevingsvoordeel werd aangetoond na behandeling met atenolol, maar omwille van de weinige nevenwerkingen en de potentiële positieve effecten werd de therapie met atenolol bij de hond van deze casus toch opgestart.

Deze casus geeft niet alleen meer inzicht in de bevindingen, behandelingsopties en gevolgen van de aanwezigheid van zowel PDA als PS bij de hond, maar benadrukt ook en voornamelijk het belang van een kwalitatief en volledig echocardiografisch onderzoek in geval van de aanwezigheid van een hartruis. Ook wanneer snel een verklaring wordt gevonden voor de aanwezige hartruis is het noodzakelijk om eventuele bijkomende hartafwijkingen uit te sluiten. In het voorliggende geval heeft de kennis van de aanwezigheid van PS de behandeling niet veranderd, maar de eigenaar kan op die manier correct worden ingelicht over de prognose en de hond kan goed worden opgevolgd om eventuele problemen in de toekomst voor te zijn.

\section{LITERATUUR}

Buchanan J.W. (2001). Patent ductus arteriosus morphology, pathogenesis, types and treatment. Journal of Veterinary Cardiology 3, 7-16. 
Bussadori C., Amberger C., Le Bobinnec G., Lombard C.W. (2000). Guidelines for the echocardiographic studies of suspected subaortic and pulmonic stenosis. Journal of Veterinary Cardiology 2, 15-22.

Bussadori C., DeMadron E., Santilli R.A., Borgarelli M. (2001). Balloon valvuloplasty in 30 dogs with pulmonic stenosis: effect of valve morphology and annular size on initial and 1-year outcome. Journal of Veterinary Internal Medicine 15, 553-558.

Côté E., Edwards N.J., Ettinger S.J., Fuentes V.L., MacDonald K.A., Scansen B.A., Sisson D.D., Abbott J.A. (2015). Management of incidentally detected heart murmurs in dogs and cats. Journal of the American Veterinary Medical Association 246, 1076-1088.

Stephenson R.B. (2012). The heart as a pump. In: Cunningham J.G., Klein B.G. (editors). Textbook of Veterinary Physiology. Fourth edition, W.B. Saunders Company, St. Louis, p. 226-241.

Francis A.J., Johnson M.J., Culshaw G.C., Corcoran B.M., Martin M.W., French A.T. (2011). Outcome in 55 dogs with pulmonic stenosis that did not undergo balloon valvuloplasty or surgery. Journal of Small Animal Practice 52, 282-288.

Freeman L., Becvarova I., Cave N., MacKay C., Nguyen P., Rama B., Takashima B., Tiffin R., Beukelen van P., Yathiraj S. (2011). WSAVA nutritional assessment guidelines. Journal of Feline Medicine and Surgery 13, 516525.

Johnson M.S., Martin M., Edwards E., French A., Henley W. (2004). Pulmonic stenosis in dogs: balloon dilatation improves clinical outcome. Journal of Veterinary Internal Medicine 18, 656-662.

Johnson M.S., Martin M. (2004). Results of balloon vulvoplasty in 40 dogs with pulmonic stenosis. Journal of Small Animal Practice 45, 148-153.
Kittleson M.D., Kienle R.D. (1998). In: Kittleson M.D., Kienle R.D. (editors). Small Animal Cardiovascular Medicine. First edition, C.V. Mosby, St. Louis, p. 248-296.

Lamy M., De Grouchy J., Schweisguth O. (1957). Genetic and non-genetic factors in the etiology of congenital heart disease: a study of 1188 cases. The American Journal of Human Genetics 9, 17-41.

Malik R., Church D.B., Hunt G.B. (1988). Valvular pulmonic stenosis in bullmastiffs. Journal of Small Animal Practice 43, 288-292.

Oliveira P., Domenech O., Silva J., Vannini S., Bussadori R., Bussadori C. (2011). Retrospective review of congenital heart disease in 976 dogs. Journal of Veterinary Internal Medicine 25, 477-483.

Patterson D.F. (1968). Epidemiologic and genetic studies of congenital heart disease in the dog. Circularion Research 23, 171-202.

Patterson D.F., Pyle R.L., Buchanan W., Trautvetter E., Abt D.A. (1971). Hereditary patent ductus arteriosus and its sequelae in dogs. Circulation Research 29, 1-13.

Patterson D.F., Haskins M.E., Schnarr W.R. (1981). Hereditary dysplasia of the pulmonary valve in beagle dogs. The American Journal of Cardiology 47, 631-641.

Schrope D.P. (2015). Prevalence of congenital heart disease in 76.301 mixed-breed dogs and 57.025 mixed-breed cats. Journal of Veterinary Cardiology 17, 192-202.

Tidholm A. (1997). Retrospective study of congenital heart defects in 151 dogs. Journal of Small Animal Practice 38, 94-98.

Van Israël N., Dukes-McEwan J., Corcoran B.M. (2002). Review of left-to-right shunting patent ductus arteriosus and short term outcome in 98 dogs. Journal of Small Animal Practice 43, 395-400. 